\title{
80 ans après l'Exposition de 1937 : la redécouverte des statues des massifs du pavillon soviétique
}

\section{Christiane Demeulenaere-Douyère}

\section{(2) OpenEdition}

Journals

Édition électronique

URL : http://journals.openedition.org/artefact/2480

DOI : $10.4000 /$ artefact.2480

ISSN : 2606-9245

Éditeur :

Association Artefact. Techniques histoire et sciences humaines, Presses universitaires du Midi

Édition imprimée

Date de publication : 6 décembre 2018

Pagination : 339-344

ISBN : 978-2-8107-0595-5

ISSN : 2273-0753

Référence électronique

Christiane Demeulenaere-Douyère, «80 ans après l'Exposition de 1937 : la redécouverte des statues des massifs du pavillon soviétique », Artefact [En ligne], 8 | 2018, mis en ligne le 21 juin 2019, consulté le 27 novembre 2020. URL : http://journals.openedition.org/artefact/2480 ; DOI : https://doi.org/ 10.4000 /artefact. 2480

\section{c) (i) $\Theta$}

Artefact, Techniques, histoire et sciences humaines est mise à disposition selon les termes de la Licence Creative Commons Attribution - Pas d'Utilisation Commerciale - Pas de Modification 4.0 International. 


\section{0 ans après l'Exposition de 1937 : la redécouverte des statues des massifs du pavillon soviétique}

\section{Christiane Demeulenaere-Douyère}

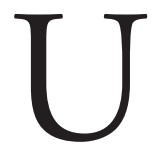

T colloque organisé à Paris à l'automne 2017, consacré au patrimoine soviétique ${ }^{1}$, a jeté un coup de projecteur nouveau sur une curieuse histoire de statues oubliées, qui mêle histoire politique, histoire de l'art, histoire des expositions internationales et recherche archéologique.

\section{Les Républiques soviétiques à l'Exposition internationale de Paris en 1937}

Dans l'imaginaire collectif, l'Exposition internationale de 1937, consacrée aux " Arts et techniques appliqués à la vie moderne ", qui clôt la longue suite des grandes expositions internationales, universelles ou thématiques,

\footnotetext{
1. "Cent ans après la Révolution d'octobre : peut-on écrire une histoire française du patrimoine soviétique ? ", colloque international organisé par l'Institut national des langues et civilisations orientales (Inalco), l'Institut CGT d'histoire sociale de la métallurgie, la Maison des métallos et le musée archéologique du Val d'Oise, avec le soutien de l'Institut national de recherches archéologiques préventives et de la Mairie de Baillet-en-France, les 12-14 octobre 2017 à Paris, sous la responsabilité de François Gentili, Taline Ter Minassian, Julia Deschepper, Emeric Tellier, Danielle Tartakowsky, Jean-Paul Demoule, Nathan Schlanger, Annie Guérin et Maria Silina. Les actes sont actuellement en préparation.
}

99 Christiane Demeulenaere-Douyère, « 80 ans après l'Exposition de 1937 », Artefact, 8 , 2018, p. 339-344. 
accueillies à Paris entre 1855 et la veille de la Seconde Guerre mondiale ${ }^{2}$, se résume souvent au face-à-face tragique de deux pavillons, celui de l'Allemagne nazie et celui de l'Union des républiques soviétiques, confrontation architecturale qui semblait annoncer les déchirements qu'allait connaitre l'Europe dans les années suivantes. Sur l'esplanade du Trocadéro, face au pavillon allemand construit par l'architecte nazi Albert Speer, massif et surmonté d'un aigle, s'élevait le pavillon de l'Union soviétique, long de 160 mètres et couronné par une tour haute de 33 mètres. Au sommet de cette tour, se dressait un gigantesque groupe sculpté, haut de 25 mètres et pesant 80 tonnes, composé de plaques en acier chromé inoxydable soudées sur une ossature en bois ${ }^{3}$. "Symbole de la nouvelle société ", cette statue, œuvre de l'artiste soviétique Vera Ignatievna Moukhina ${ }^{4}$, représentait un jeune couple emblématique, l'ouvrier et la kolkhozienne, brandissant dans un même élan le marteau et la faucille ${ }^{5}$ (Fig. 1).

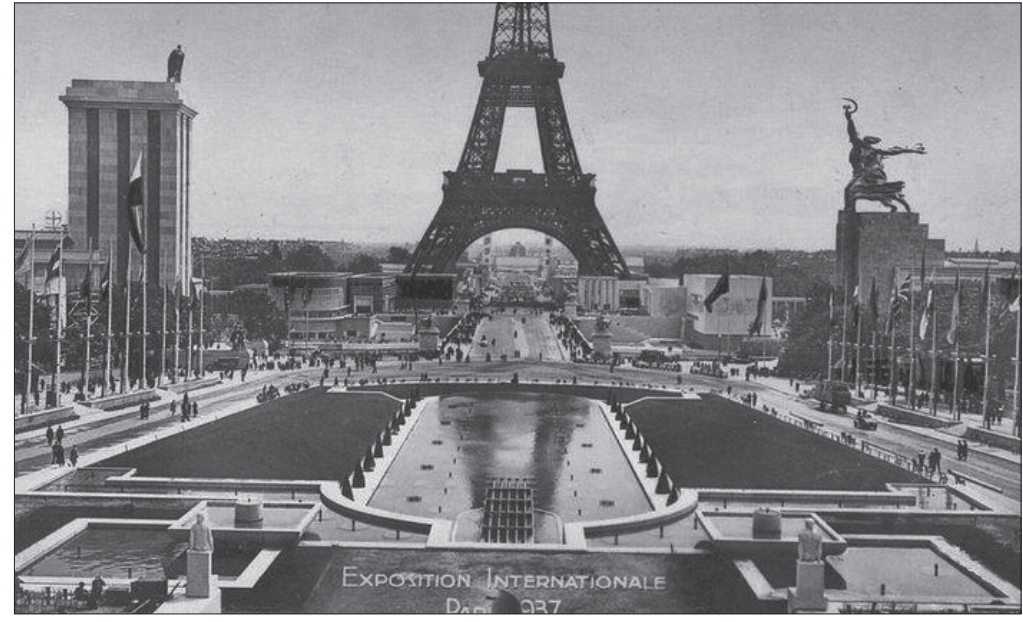

Fig. 1. - Exposition internationale de 1937, à Paris, vue générale

Carte postale

2. Christiane Demeulenaere-Douyère, «Paris et les expositions universelles », conférence donnée dans le cycle "Paris : Paris de la Restauration à la Grande Guerre » de l'Institut d'études avancées (IEA) de Paris, dans le cadre des « mardis » de l'hôtel de Lauzun, le 11 avril 2017 ; vidéo en ligne : http://www.paris-iea.fr/fr/liste-des-videos/paris-de-la-restauration-a-la-grande-guerre-10975.

3. C'est la première manifestation publique de cette technique artistique.

4. Vera Ignatievna Moukhina (1889-1953) ; élève d'Antoine Bourdelle, elle reçut en 1941 le prix Staline pour ce groupe statuaire et fut désignée, en 1943, "artiste du peuple de l'URSS ». Elle est considérée comme l'un des plus grands sculpteurs de l'ère soviétique.

5. Devenu le symbole du "réalisme socialiste " soviétique, ce groupe statuaire a été récupéré par l'URSS à la fin de l'exposition internationale ; il est aujourd'hui exposé à Moscou au sommet d'une reconstitution du pavillon soviétique de l'Exposition de 1937, transformé en musée. 
On se souvient moins des deux massifs (ou "propylées ") latéraux, longs d'une quinzaine de mètres, qui encadraient l'entrée du pavillon (Fig. 2).

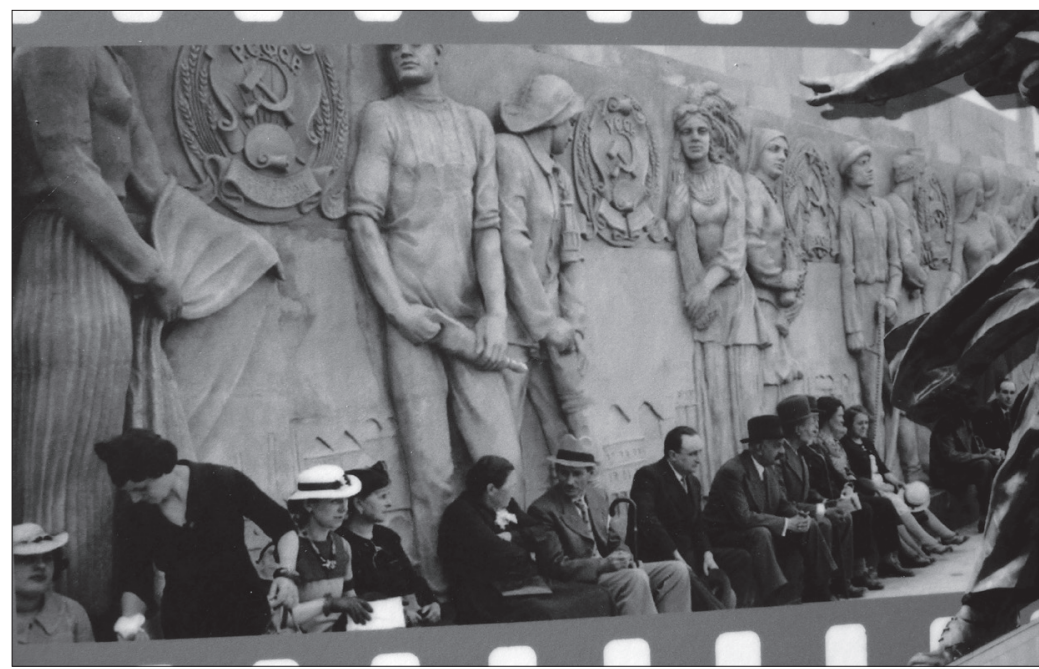

\section{Fig. 2. Vue d'un des propylées du pavillon soviétique dans l'Exposition internationale de 1937}

Reproduction d'une photographie non localisée présentée dans le dispositif pédagogique actuel du site de Baillet.

Pour signifier le caractère fédéraliste de l'URSS, ils présentaient des allégories des onze républiques soviétiques de l'époque sous forme de bas-reliefs, œuvre du sculpteur Joseph Tchaïkov ${ }^{6}$, qui représentaient des travailleurs issus du peuple soviétique, hommes et femmes, en couples, symbolisant principalement l'agriculture (fileuses, pasteurs, agriculteurs, pêcheurs...) et l'industrie (mineurs, tractoristes...), souvent identifiables à leurs vêtements traditionnels, mais aussi aviateurs, musiciens et enfants, etc. Ainsi, la république d'Ukraine était représentée par un mineur coiffé d'un large chapeau de cuir, qui portait au cou une lampe et s'appuyait sur un marteau-piqueur, et par une femme portant une gerbe de blé ; l'Azerbaïdjan était figuré par un homme coiffé d'une toque en laine se livrant à une activité de forage, et une femme à la tête ceinte d'un foulard orné de médailles occupée à la récolte de coton ; le représentant turkmène était un cavalier, coiffé d'une toque conique caractéristique, qui embrassait l'encolure de son

6. Joseph Moiseevitch Tchaïkov (1888-1986) ; il fut, dans les années 1930, une des figures du réalisme dans la sculpture soviétique, connu essentiellement pour ses représentations d'athlètes. 
cheval... Chaque république était également symbolisée par un blason. Par ailleurs, sur les petits côtés des massifs, en façade du pavillon, se trouvaient deux compositions, figurant l'une le Sport et l'Armée et l'autre la Musique et la Danse (de nombreux fragments ont été retrouvés) dont un groupe de musiciens dominé par le violoniste (Fig. XXIV à XXVIII, cahier couleur). Ces œuvres, réalisées en ciment métallisé au pistolet, comptaient parmi les premiers prototypes de cette technique.

À l'issue de l'Exposition internationale, tandis que l'ouvrier et la kolkhozienne rejoignaient Moscou, les deux massifs sculptés restèrent en France. Le massif nord était offert par l'URSS à la CGT et parvenait particulièrement entre les mains du Syndicat de la Métallurgie de la Seine qui le déposa dans le domaine du château de Baillet-en-France (aujourd'hui Val-d'Oise) qu'il acquérait en cette même année 1937 pour héberger son centre de vacances (Fig. 3).

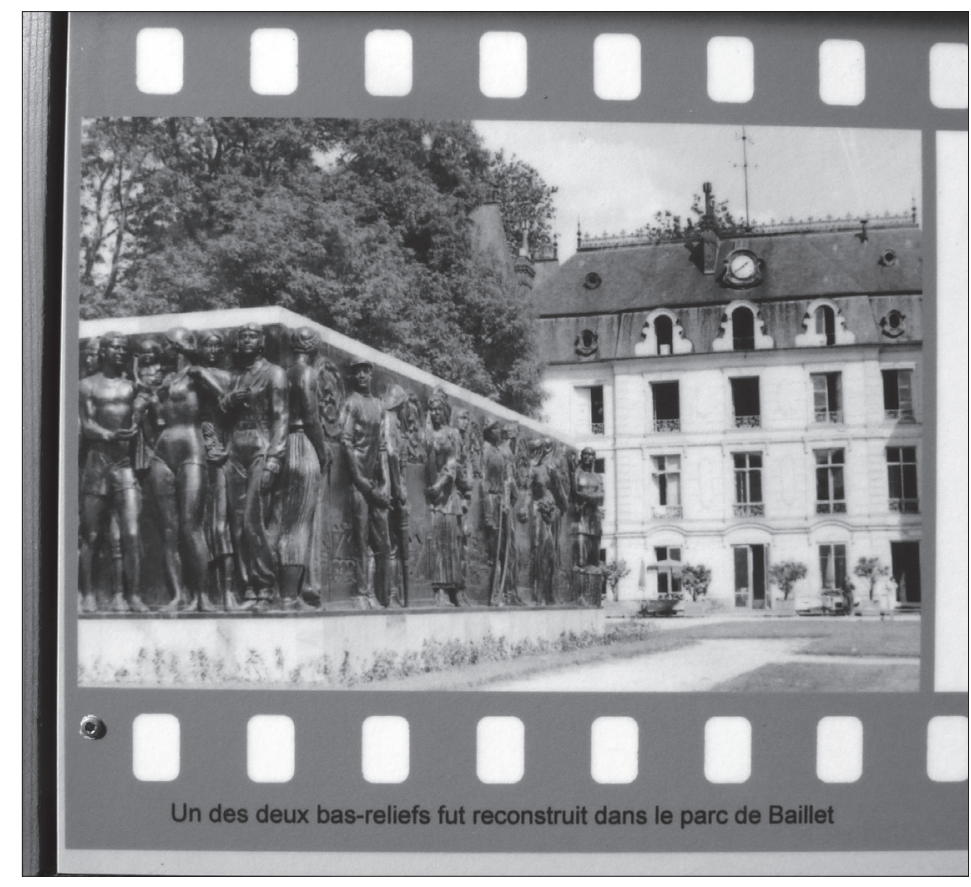

Fig. 3. Le propylée installé devant le château de Baillet après l'Exposition

Reproduction d'une photographie non localisée présentée dans le dispositif pédagogique actuel du site de Baillet 
Puis survint la Seconde Guerre mondiale. En France, le PCF et la CGT étaient interdits et, en 1940, le domaine de Baillet confisqué par l'État français qui en fit un camp d'internement pour prisonniers politiques (élus et militants communistes), puis un centre de jeunesse pétainiste. Au printemps 1941, les sculptures furent volontairement brisées à coups de marteau. À la Libération, alors que le site devenait un camp de réfugiés politiques, leurs vestiges furent un temps exposés au sol, puis jetés dans l'ancienne glacière du château qui fut murée. Ils sombrèrent alors dans un long oubli.

\section{La mise au jour des bas-reliefs et leur valorisation}

Dans les années 1990, le château de Baillet fut détruit dans un incendie accidentel et le parc racheté par la municipalité qui projetait d'établir un lotissement sur une partie du domaine. Un diagnostic archéologique fut donc entrepris. En 2004, François Gentili, archéologue de l'INRAP et spécialiste de l'habitat seigneurial médiéval, explora les glacières du château'. Dans l'une d'elles, datant du XvII ${ }^{\mathrm{e}}$ siècle, dont l'entrée avait été murée, il eut la surprise de trouver un amoncellement impressionnant d'éléments sculptés en béton, de grandes statues brisées (faisant initialement plus de $3 \mathrm{~m}$ de haut), têtes, membres, troncs, reliefs et médaillons... Certains éléments (marteau, faucille, tracteur...) l'incitèrent à envisager un monument de grande taille, indiscutablement soviétique et postérieur à 1936. Des recherches ultérieures confirmèrent qu'il s'agissait bien d'éléments du pavillon soviétique de l'Exposition internationale des Arts et techniques dans la vie moderne, présentée à Paris en 1937, dont tout le monde avait perdu jusqu'au souvenir.

Témoignage unique de l'art soviétique en France, et lointains souvenirs de la dernière grande exposition internationale accueillie à Paris, il y a tout juste 80 ans, ces statues furent remontées au jour en 2009. Elles furent stockées dans les dépôts de l'INRAP, restaurées, et enfin installées,

\footnotetext{
7. Les glacières sont des puits dans lesquels on entassait et conservait de la glace récoltée en hiver sur les étangs.
} 
depuis 2010, au musée archéologique départemental de Guiry-en-Vexin ${ }^{8}$, dans une scénographie à la fois impressionnante et poétique. La redécouverte inattendue de ces statues leur a permis ainsi d'être présentées au public dans plusieurs expositions récentes: Lénine, Staline et la musique (23 octobre 2010-16 janvier 2011, à la Cité de la musique-Philharmonie), Ruines et vestiges (2011, à Guiry-en-Vexin).

L'origine fantasmatique de ces statues, leur histoire extraordinaire, le romanesque de leur redécouverte 9 , leur beauté formelle et évocatrice et leurs dimensions colossales seront autant d'incitations, nous l'espérons, à les montrer plus souvent au public, notamment dans des expositions, et pour chacun de nous à prendre le chemin de Guiry-en-Vexin.

\section{Auteur}

Conservateur général du patrimoine (h) et membre correspondant du Centre Alexandre-Koyré, Paris ; spécialiste des expositions internationales. Contact : christiane.demeulenaere@gmail.com.

8. Musée archéologique départemental du Val d’Oise, 4 place du Château, 95450 Guiry-en-Vexin ; site : http://www.valdoise.fr/608-le-musee-archeologique-departemental-du-val-d-oise.htm.

9. Sur l'histoire et la redécouverte des statues, "Vestiges soviétiques à Baillet-en-France », interview de François Gentili, Val d'Oise. Émotions, n 2, 2017, p. 29-31 ; plaquette Inrap, "La découverte des bas-reliefs du pavillon soviétique de l'Exposition internationale de 1937 ", Inrap CentreÎle-de-France, s. d. ; Maria TсновANov, "Les incroyables aventures des statues soviétiques de l'exposition de 1937 ", Russia Beyond, 17 octobre 2017, https://fr.rbth.com/histoire/79316-statues-sovietiques-exposition-1937-paris\# ; à voir également le remarquable site Internet de la ville de Baillet-en-France : https://baillet-statues-sovietiques.jimdo.com. 